Résumés des conférences et travaux

\title{
Manuscrits hébreux et judéo-arabes médiévaux
}

Conférences de l'année 2014-2015

\section{Judith Olszowy-Schlanger}

\section{OpenEdition \\ Journals}

\section{Édition électronique}

URL : https://journals.openedition.org/ashp/1805

DOI : 10.4000/ashp.1805

ISSN : 1969-6310

\section{Éditeur}

Publications de l'École Pratique des Hautes Études

Édition imprimée

Date de publication : 1 septembre 2016

Pagination : 24-25

ISSN : 0766-0677

Référence électronique

Judith Olszowy-Schlanger, "Manuscrits hébreux et judéo-arabes médiévaux », Annuaire de l'École pratique des hautes études (EPHE), Section des sciences historiques et philologiques [En ligne], 147 | 2016, mis en ligne le 21 septembre 2016, consulté le 06 juillet 2021. URL : http://journals.openedition.org/ ashp/1805; DOI : https://doi.org/10.4000/ashp.1805 


\title{
MANUSCRITS HÉBREUX ET JUDÉO-ARABES MÉDIÉVAUX
}

\author{
Directeur d'études : $\mathrm{M}^{\text {me }}$ Judith Olszowy-Schlanger
}

Programme de l'année 2014-2015 : Contrats de vente en caractères hébraïques de la Geniza du Caire et de l'Angleterre médiévale : pluralisme légal et formules juridiques.

Cette année nos travaux ont porté sur les contrats de ventes immobilières. Nous avons étudié, à partir d'images de haute qualité, des contrats écrits en Égypte et provenant de la Geniza du Caire ainsi que des contrats rédigés dans l'Angleterre médiévale. Le but de cette étude était tout d'abord de poursuivre la formation en diplomatique hébraïque, en analysant les aspects matériels, les écritures, la typologie des transactions et les formules juridiques des documents. Il s'agissait ensuite de comprendre le fonctionnement des contrats dans leurs contextes historiques et légaux respectifs. L'étude des contrats provenant des zones culturelles différentes fournit en effet un cadre comparatif qui permet à la fois d'apprécier la continuité des traditions documentaires entre les communautés différentes et géographiquement éloignées de la diaspora et l'impact de la société environnante non juive dans le domaine des pratiques juridiques et documentaires.

Dans cette perspective, on constate tout d'abord que les contrats de ventes immobilières sont rares dans le vaste corpus des documents juridiques de la Geniza du Caire. Seulement quelques dizaines de contrats de vente émanant du tribunal juif et écrits selon les formules rabbiniques ont été identifiés parmi les quelques dix mille écrits pragmatiques provenant de la Geniza du Caire. En revanche, les transactions immobilières sont bien représentées dans le plus petit corpus de documents juridiques hébraïques de l'Angleterre médiévale (sur 258 documents en hébreu ou bilingues, latin et hébreu, 47 , donc plus de $18 \%$, sont des ventes immobilières). Cette différence reflète un contexte légal différent.

Les contrats juridiques engageant les juifs sont en principe écrits par des personnes qui maîtrisent l'art de l'écriture ainsi que le maniement de formules juridiques. Leur validité est confirmée par des témoins juifs. Tout cela fonctionne dans l'univers des tribunaux rabbiniques qui supervisent la production des actes et veillent à leur exécution régulière. Cependant, l'étendue des activités et du pouvoir des tribunaux rabbiniques, leurs droits et leur organisation varient selon les communautés au cours du Moyen Âge. Selon les pays et époques différentes, l'autonomie des tribunaux juifs est plus au moins affirmée, mais dans tous les cas, elle est emboîtée dans le système juridique de la société environnante. Ce système permet aux juifs de fonctionner comme une communauté définie au sein de la société qui lui accorde un certain statut et des privilèges et impose certaines obligations. En Égypte, en tant qu'une minorité protégée (dhimmis, s'appliquant aux juifs et chrétiens), les juifs et leurs tribunaux rabbiniques bien établis jouissaient d'une autonomie relativement grande accordée par 
les autorités musulmanes. En Angleterre, les contrats écrits en hébreu, validés par les témoins juifs, parfois certifiés par un tribunal de trois juges convoqués et nommés ad hoc, étaient reconnus par l'administration et la justice de la Couronne. Cependant, dès la fin $\mathrm{du} \mathrm{XII}{ }^{\mathrm{e}}$ siècle, toutes les transactions financières concernant les juifs, y compris les ventes immobilières, n'étaient valides que si elles étaient certifiées et archivées par une institution émanant de l'Échiquier et gérée au niveau des villes différentes pas les représentants du roi, les sheriffs.

Dans les deux cas, les juifs avaient le droit de recourir directement aux tribunaux non juifs. Les juifs dans les deux pays de la diaspora vivaient et fonctionnaient dans une réalité juridique double : soumis à des degrés différents à la loi talmudique, ils sont aussi sujets à la loi du pays de leur résidence, dont les décisions sont, volens nolens, acceptées par les tribunaux rabbiniques, selon le principe de dina de-malkhuta dina (« la loi du pays et la loi ») énoncé dans le Talmud de Babylonie (Gittin 10b)

C'est précisément cette situation de bi-légalisme qui explique la basse proportion des contrats de vente dans le corpus égyptien et un taux bien plus élevé dans le corpus anglais. En effet, si l'autonomie des tribunaux rabbinique fut plus grande en Égypte, les ventes immobilières, contrairement à d'autres types de contrats passés entre les parties juives, étaient soumises à une taxe versée aux autorités musulmanes. Il était probablement plus simple et moins couteux de s'adresser directement aux autorités musulmanes. Les contrats de vente entre les individus juifs étaient donc souvent dressés devant le tribunal du $q \bar{a} d \bar{l}$, en arabe et selon le formulaire des contrats musulmans. De tels documents ne sont que rarement conservés dans la Geniza du Caire qui a accueilli principalement des contenus des archives communautaires et privées juives. Quant aux contrats anglais, comme les autres transactions financières, les ventes immobilières en hébreu étaient enregistrées par les fonctionnaires juifs et chrétiens associés à une archa et nommés par le roi. Ces documents, bien qu'ayant une forme et portant des signes de validité propres aux documents juifs, appartiennent donc aussi au système légal et économique non juif. C'est grâce à leur conservation dans les archives de l'administration royale que ces documents hébreux nous sont parvenus.

Mis à part leur contexte d'élaboration, nos travaux ont porté cette année sur les formules de contrats de vente. La comparaison entre les documents provenant des lieux différents de la diaspora montre d'une part la stabilité des formulaires de base qui constituent l'héritage de la tradition développée dans les académies rabbiniques (yeshivot) d'Iraq à l'époque talmudique et au cours des premiers siècles après la conquête arabe, et d'autre part des innovations qui reflètent la situation légale ou coutumes d'une communauté particulière. Ces innovations correspondent souvent à l'adaptation de la tradition documentaire juive en hébreu et araméen aux certains éléments juridiques du monde non juif environnant et aux exigences des formulaires non juifs en arabe, ou en latin ou français vernaculaire. Ainsi, l'étude comparative des formules nous a permis de nous interroger d'une part sur la transmission des savoirs légaux à travers la diaspora médiévale et d'autre part sur la plasticité des formulaires juifs capables d'intégrer des formules et coutumes non juives aux côtés des formules juives traditionnelles.

L'étude des documents concernant les transactions immobilières se poursuivra l'année prochaine avec les documents hébreux de la Cologne médiévale. 